\title{
Effect of Fe addition on transformation temperatures and hardness of NiMnGa magnetic shape memory alloys
}

\author{
F. CHEN, H. B. WANG, Y. F. ZHENG, W. CAI, L. C. ZHAO \\ School of Materials Science and Engineering, Harbin Institute of Technology, Harbin, 150001, \\ People's Republic of China
}

In recent years, ferromagnetic shape memory alloys (FSMAs) have been widely investigated in many countries [1-4]. Of the developed FSMAs, NiMnGa alloys have been found to exhibit nearly $10 \%$ magnetic-fieldinduced strain which is the maximum obtained MFIS in these FSMAs [5]. Based on NiMnGa alloys, researchers have developed new ferromagnetic shape memory alloys, i.e., NiMnFeGa alloys [6, 7]. The structure, shape memory effect, and magnetic properties of Fe-doped NiMnGa alloys have been studied. It is assumed that the addition of Fe element enhances the alloy plasticity without sacrificing its magnetic and thermoelastic properties [6]. However, little work has been devoted to studying transformation behavior and the mechanical properties of polycrystalline Fe-doped NiMnGa alloys. The aim of the present letter is to study the effect of additions of $\mathrm{Fe}$ on transformation behavior and the hardness of NiMnGa alloys.

A range of alloys with the nominal composition of $\mathrm{Ni}_{48.7} \mathrm{Mn}_{30.1-x} \mathrm{Fe}_{x} \mathrm{Ga}_{21.2}$ (at $\left.\%\right)(x=0,2,5,8,11)$, each weighing about $80 \mathrm{~g}$, were prepared. The alloys were fabricated by arc melting under an argon atmosphere using appropriate quantities of nickel (99.99\% purity), manganese ( $99.9 \%$ purity), iron ( $99.9 \%$ purity) and gallium ( $99.99 \%$ purity). The ingots obtained were sealed in a quartz tube under a vacuum, followed by annealing at $1123 \mathrm{~K}$ for $24 \mathrm{hrs}$ and quenched into ice water for homogeneity. Rectangular samples $4 \times 4 \times 6$ $\mathrm{mm}$ were cut from the post-treated ingots for hardness measurements.

Some $10 \mathrm{mg}$ samples were taken from the ingots for DSC measurements. The transformation temperatures were determined by differential scanning calorimetry using a TA-2920. The heating and cooling rates were $10 \mathrm{~K} / \mathrm{min}$. The crystal structure at room temperature was confirmed by powder X-ray diffraction using D/MAX-RA X-ray diffractometer with $\mathrm{Cu} \mathrm{K}_{\alpha}$ radiation. Micro Vickers hardness (HV) of eight points was measured using a Akashi HM-102 Vickers Hardness Tester. The applied load and time were $200 \mathrm{~g}$ and $15 \mathrm{~s}$, respectively. The HV values were averaged excluding the highest and lowest values [8].

Table I summarizes the transformation temperatures measured by DSC analysis in $\mathrm{Ni}_{48.7} \mathrm{Mn}_{30.1-x}$ $\mathrm{Fe}_{x} \mathrm{Ga}_{21.2}$ alloys $(x=0,2,5,8,11)$. It can be seen, at room temperature, that the parent phase and martensite coexist in the $\mathrm{Ni}_{48.7} \mathrm{Mn}_{30.1} \mathrm{Ga}_{21.2}$ alloy and the $\mathrm{Ni}_{48.7} \mathrm{Mn}_{28.1} \mathrm{Fe}_{2} \mathrm{Ga}_{21.2}$ alloys, whereas in the other three alloys only the parent phase exists. The results are in agreement with X-ray diffraction results in Fig. 1. $\mathrm{X}$-ray patterns depict that the cubic parent phase and tetragonal martensite coexist when $x=0,2$, while only the cubic parent phase exists when $x=5,8,11$. As shown in Table I, the thermal hysteresis of these five alloys are $-1.38,-3.30,0.46,2.60$ and $2.20^{\circ} \mathrm{C}$, respectively. For the $\mathrm{Ni}_{48.7} \mathrm{Mn}_{30.1} \mathrm{Ga}_{21.2}$ alloy and the $\mathrm{Ni}_{48.7} \mathrm{Mn}_{28.1} \mathrm{Fe}_{2} \mathrm{Ga}_{21.2}$ alloys, the thermal hysteresis is negative. Hence Fe-doped NiMnGa alloys exhibit very narrow thermal hysteresis which means that the chemical energy of the phase transformation is very small. The narrow thermal hysteresis also shows that the driving force for inducing the martensitic transformation in Fe-doped NiMnGa alloy is very small. Wayman [9] divided thermal transformations into two types: the first is $A_{\mathrm{f}}>A_{\mathrm{s}}>M_{\mathrm{s}}>M_{\mathrm{f}}$ while the second is $A_{\mathrm{f}}>M_{\mathrm{S}}>A_{\mathrm{s}}>M_{\mathrm{f}}$. From Table I it can be seen that the first two alloys belong to the second type of thermal transformation, while the other three alloys belong to the first type of thermal transformation. In addition, only single forward and reverse transformation are determined by DSC curves.

Fig. 2 depicts the phase transformation temperatures vs. $\mathrm{Fe}$ content for $\mathrm{Ni}_{48.7} \mathrm{Mn}_{30.1-x} \mathrm{Fe}_{x} \mathrm{Ga}_{21.2}$ alloys $(x=0,2,5,8,11)$. It can be seen that with increase of $\mathrm{Fe}$ content all the transformation temperatures, $M_{\mathrm{s}}$ (martensitic transformation start temperature), $M_{\mathrm{f}}$ (martensitic transformation finish temperature), $A_{\mathrm{s}}$ (reverse martensitic transformation start temperature), and $\mathrm{A}_{f}$ (reverse martensitic transformation finish temperature), decrease. The relationship between $M_{\mathrm{s}}$ temperature and Fe content is nearly linear, varing from $26.40{ }^{\circ} \mathrm{C}$ for $\mathrm{Ni}_{48.7} \mathrm{Mn}_{30.1} \mathrm{Ga}_{21.2}$ without $\mathrm{Fe}$ to $-55.0{ }^{\circ} \mathrm{C}$ for $\mathrm{Ni}_{48.7} \mathrm{Mn}_{19.1} \mathrm{Fe}_{11} \mathrm{Ga}_{21.2}$ which has the maximum $\mathrm{Fe}$ content.

Fig. 3 exhibits the relationship between transformation temperatures and valence electron numbers per atom of $\mathrm{Ni}_{48.7} \mathrm{Mn}_{30.1-x} \mathrm{Fe}_{x} \mathrm{Ga}_{21.2}$ alloys ( $x=$ $0,2,5,8,11)$ and the shape of the curves is similar to Fig. 2. The tendency is clear that all transformation temperatures decrease with increase of electronic concentration in these five alloys, and the increasing rate is also basically consistent with the change of the electronic concentration. Here, it is assumed that the number of valence electrons per atom for $\mathrm{Ni}, \mathrm{Mn}, \mathrm{Fe}$, and $\mathrm{Ga}$ atoms is $10(3 \mathrm{~d} 84 \mathrm{~s} 2), 7(3 \mathrm{~d} 54 \mathrm{~s} 2), 8(3 \mathrm{~d} 64 \mathrm{~s} 2)$ and $3(3 \mathrm{~s} 24 \mathrm{p} 1)$, respectively.

It is believed that two factors, the conduction electronic concentrations [10] and the size factor [11], 
TABLE I Transformation characteristics of $\mathrm{Ni}_{48.7} \mathrm{Mn}_{30.1-x} \mathrm{Fe}_{x} \mathrm{Ga}_{21.2}$ alloys

\begin{tabular}{rrrrrrr}
\hline Composition & $e / a$ & $M_{\mathrm{S}}\left({ }^{\circ} \mathrm{C}\right)$ & $M_{\mathrm{f}}\left({ }^{\circ} \mathrm{C}\right)$ & $A_{\mathrm{S}}\left({ }^{\circ} \mathrm{C}\right)$ & $A_{\mathrm{f}}\left({ }^{\circ} \mathrm{C}\right)$ & $A_{\mathrm{S}}-M_{\mathrm{S}}\left({ }^{\circ} \mathrm{C}\right)$ \\
\hline $\mathrm{Ni}_{48.7} \mathrm{Mn}_{30.1}$ & 7.613 & 26.38 & 19.45 & 25.00 & 32.47 & -1.38 \\
$\mathrm{Ga}_{21.2}$ & & & & & & \\
$\mathrm{Ni}_{48.7} \mathrm{Mn}_{28.1}$ & 7.633 & 21.20 & 11.80 & 17.90 & 25.60 & -3.30 \\
$\mathrm{Fe}_{2} \mathrm{Ga}_{21.2}$ & & & & & & \\
$\mathrm{Ni}_{48.7} \mathrm{Mn}_{25.1}$ & 7.663 & 7.40 & 1.40 & 7.86 & 12.80 & 0.46 \\
$\mathrm{Fe}_{5} \mathrm{Ga}_{21.2}$ & & & & & & \\
$\mathrm{Ni}_{48.7} \mathrm{Mn}_{22.1}$ & 7.693 & -40.00 & -44.20 & -37.40 & -33.50 & 2.60 \\
$\mathrm{Fe}_{8} \mathrm{Ga}_{21.2}$ & & & & & & \\
$\mathrm{Ni}_{48.7} \mathrm{Mn}_{19.1}$ & 7.723 & -55.00 & -61.00 & -52.80 & -48.40 & 2.20 \\
$\mathrm{Fe}_{11} \mathrm{Ga}_{21.2}$ & & & & & &
\end{tabular}

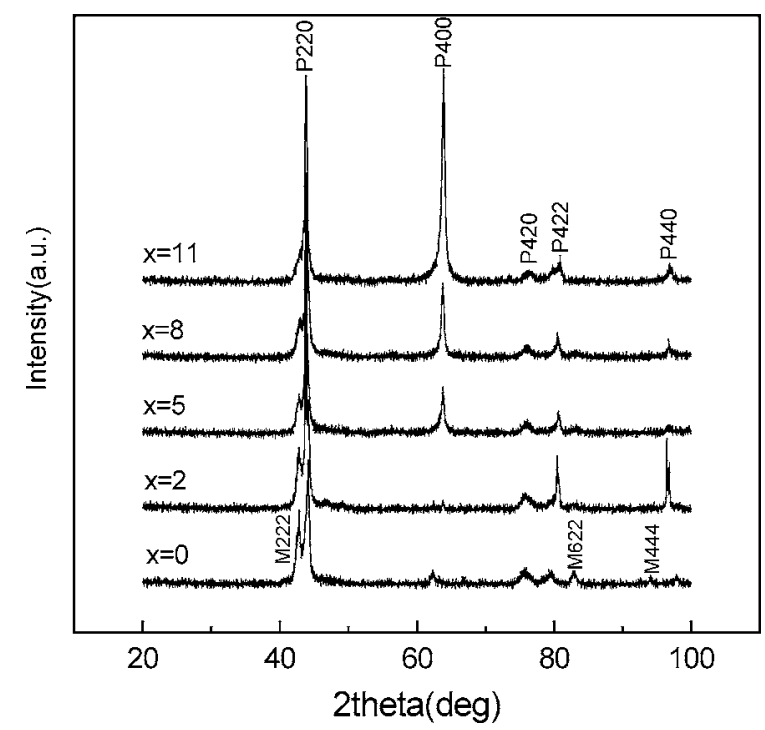

Figure 1 X-ray diffraction patterns of $\mathrm{Ni}_{48.7} \mathrm{Mn}_{30.1-x} \mathrm{Fe}_{x} \mathrm{Ga}_{21.2}$ alloys $(x=0,2,5,8,11)$ samples at room temperature.

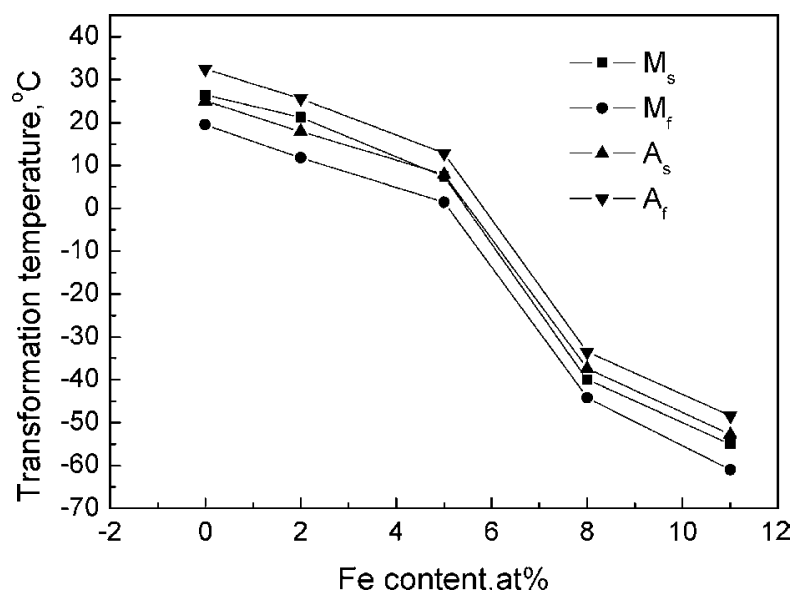

Figure 2 The phase transformation temperatures $M_{\mathrm{s}}, M_{\mathrm{f}}, A_{\mathrm{s}}, A_{\mathrm{f}}$ versus Fe content for $\mathrm{Ni}_{48.7} \mathrm{Mn}_{30.1-x} \mathrm{Fe}_{x} \mathrm{Ga}_{21.2}$ alloys $(x=0,2,5,8,11)$.

influence the transformation temperatures in $\mathrm{NiMnGa}$ alloys. Jin et al. [10] found that the relationship between martensitic transformation temperature and the average number of valence electrons per atom is as follows: $T_{\text {mart }}=702.5(e / a)-5067 \mathrm{~K}$, which predicted that the $M_{\mathrm{s}}$ temperature increases with increasing $e / a$. However the present letter shows a contrary finding to Jin's work. The effect of size factor was demonstrated in the

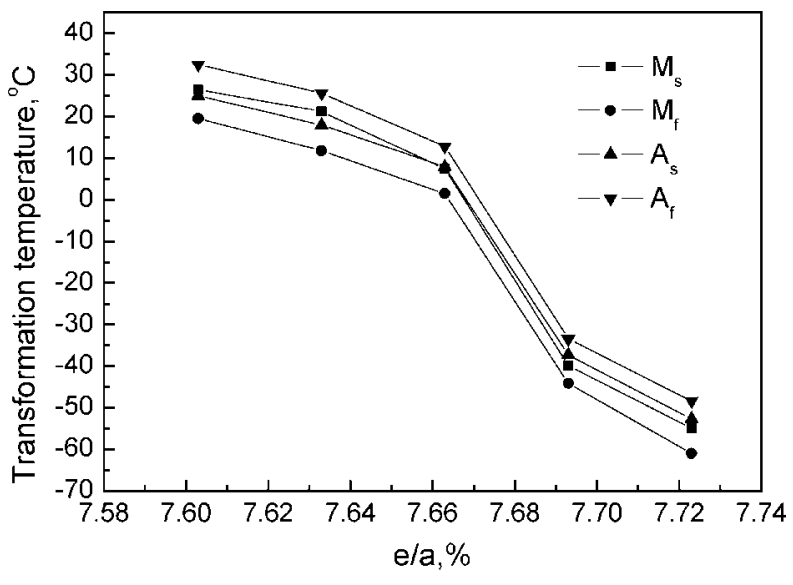

Figure 3 The phase transformation temperatures $M_{\mathrm{s}}, M_{\mathrm{f}}, A_{\mathrm{s}}, A_{\mathrm{f}}$ versus $e / a$ for $\mathrm{Ni}_{48.7} \mathrm{Mn}_{30.1-x} \mathrm{Fe}_{x} \mathrm{Ga}_{21.2}$ alloys $(x=0,2,5,8,11)$.

$\mathrm{Ni}_{2} \mathrm{MnGa}_{x} \mathrm{In}_{1-x}$ system [11], where the decrease of the unit-cell volumes results in the increase of martensitic transformation temperatures when the small Ga atom substitutes for the large In atom. The atomic radius for $\mathrm{Ni}, \mathrm{Mn}, \mathrm{Ga}$, and Fe is $0.125,0.135,0.141$ and $0.126 \mathrm{~nm}$, respectively. A similar decrease of the unit-cell volumes would be observed as the smaller Fe atom substitutes for $\mathrm{Mn}$. The martensitic transformation temperatures increase as the unit-cell volumes decrease. According to the above theory, Fe substituting for the large $\mathrm{Mn}$ atom will lead to a large increase of the transformation temperatures. However in the present paper, we obtain contrary results. From the above discussion, it is believed that the mechanism of the effect of Fe additions on transformation temperatures is very complex, which cannot be explained only by the size factor and conduction electronic concentrations.

As depicted in Fig. 4, with increasing the Fe content from $0 \%$ (at $\%$ ) to $5 \%$ (at $\%$ ), the hardness increases abruptly but it changes only slightly from 5\% (at\%) to $11 \%$ (at\%). Hosoda et al. [8] thought that the hardness, in aged Ni-Mn-Ga alloys, would increase with the amount of antistructure defect which is formed by excess atoms substituting on other sublattice sites unoccupied by constitutional elements. That is to say if $\mathrm{Ni}, \mathrm{Mn}, \mathrm{Ga}$, and $\mathrm{Fe}$ atoms occupy each other's sites,

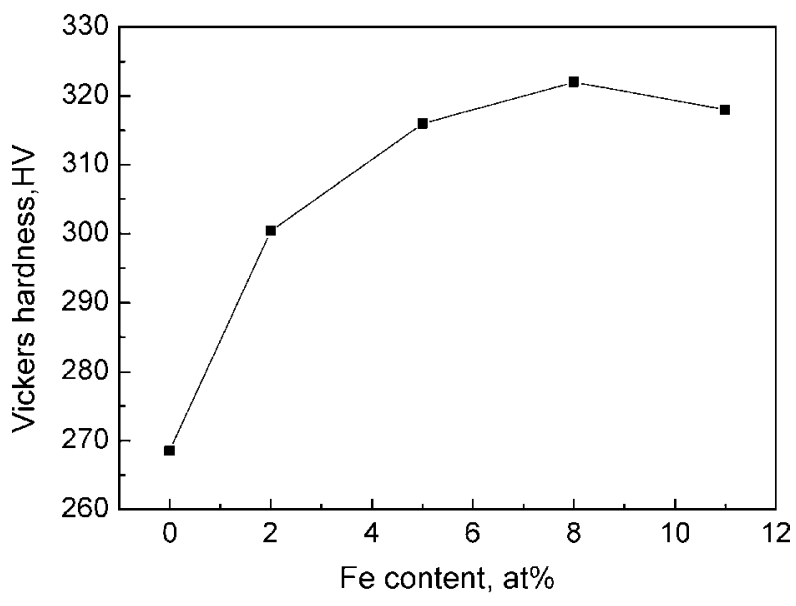

Figure 4 Vickers hardness as a function of $\mathrm{Fe}$ content for $\mathrm{Ni}_{48.7} \mathrm{Mn}_{30.1-x} \mathrm{Fe}_{x} \mathrm{Ga}_{21.2}$ alloys $(x=0,2,5,8,11)$. 
it will cause antistructure defects. In the present letter, the small $\mathrm{Fe}$ atom is added to the NiMnGa alloy to replace the large $\mathrm{Mn}$ atom, which is advantageous for the formation of antistructure defects. More addition of $\mathrm{Fe}$ atoms will cause more antistructure defects and thus increase the hardness. Considering the X-ray patterns and DSC results, the increase of Fe improves the strength of the parent phase.

We believed that the decrease of $M_{\mathrm{s}}$ temperatures can be explained as follows: (1) In conventional shape memory alloys, such as NiTi alloy, Wu [12] studied the effect of the addition of a third element on the martensitic transformation temperature, and found that the martensitic transformation temperature increased with increasing degree of ordering of the parent phase. It is known that NiMnGa alloy is an ordered Heusler type intermetallic compound with $\mathrm{L} 2{ }_{1}$ crystal structure [13]. The structure of the martensite comes from the cubic L2 1 type structure due to the diffusionless martensitic transformation. The sites of $\mathrm{Ni}, \mathrm{Mn}$, and $\mathrm{Ga}$ are the same as those in the $\mathrm{L} 2{ }_{1}$ type structure. The addition of Fe does not change the crystal structure of NiMnGa alloys and the structure of Fe-doped NiMnGa alloys is $\mathrm{L} 2{ }_{1}$ type as well. The increase of the Fe content results in a decrease in the degree of ordering so that the martensitic transformation temperatures decreases. (2) Crystallographic characteristics of the martensitic transformations are now well understood by the phenomenological crystallographic theory. This theory shows that a lattice invariant shear plays an important role in the martensitic transformation [14], and the shear energy is connected with the strength of the parent phase, which suggests that with increasing strength of the parent phase the shear energy increases. Therefore more driving force is needed for the martensitic transformation, which results in the decrease of $M_{\mathrm{S}}$ [15]. In the present letter, the hardness values measured at room temperature show that the strength of the parent phase of different compositions increase with increasing Fe addition, therefore according to the theory in [15], the $M_{\mathrm{S}}$ temperature decreases with increasing Fe addition.

Based on the above results and discussion, the conclusions are as follows: (1) increased Fe content decreases all the transformation temperatures as it replaces Mn. No extra phase transformation is observed;
(2) with increasing $\mathrm{Fe}$ content the hardness of parent phase increases which indicates the same dependence of strength of parent phase on Fe content. (3) The effect of $\mathrm{Fe}$ addition on transformation temperatures may be caused by the fall of ordering degree and the increase of strength with the increase of $\mathrm{Fe}$ content.

\section{Acknowledgment}

This work is supported by National Natural Science Foundation of China (No. 5013010).

\section{References}

1. V. A. CHERNENKO, E. CESARI, V. V. KOKORIN and I. N. VITEN KO, Scr. Metall. Mater. 33 (1995) 1239.

2. V. A. CHERNENKO and V. V. KOKORIN, in Proceedings of the International Conference on Martensitic Transformation 1992 (Monterey Institute for Advanced Studies, Monterey, California, USA, 1993) p. 1205.

3. K. ULlAKKO, J. K. HUANG, V. V. KOKORIN and R. C. O'HANDLEY, Scr. Mater. 36 (1997) 1133.

4. R. C. O'Handley, J. Appl. Phys. 83 (1998) 3263.

5. A. SOZINOV, A. A. LIKHACHEV, N. LANSKA and K. ULlA K K O, Appl. Phys. Lett. 80 (2002) 1746.

6. A. A. CHERECHUKIN, I. E. DIKSHTEIN, D. I. ERMAKOV, A. V. GLEBOV, V. V. KOLEDOV, D. A. KOSOLAPOV, V. G. SHAVROV, A. A. TULAIKOVA, E. P. KRASNOPEROV and T. TAKAGI, Phys. Lett. A 291 (2001) 175.

7. W. H. WANG, J. L. CHEN, L. AO, Z. H. LIU and W. S. ZHAN, Appl. Phys. Lett. 80 (2002) 634

8. H. HOSODA, K. WAKASHIMA, T. SUGIMOTO and S. MIY AZA KI, Mater. Trans. JIM. 43 (2002) 852.

9. C. M. W A Y M A N, "Suppl. Trans. JIM,' edited by Japan Inst. Met. 1976, p. 159.

10. X. JiN, M. MARIONI, D. BONO, S. M. ALLEN, R. C. O'HANDley, T. Y. HSU, J. Appl. Phys. 91 (2002) 8222.

11. V. V. KOKORIN, I. A. OSIPENKO and T.V. SHIRINA, Phys. Met. Metall. 67 (1989) 173.

12. J. X. WU, B. H. JIANG and T. Y. HSU, Acta Metall. 6 (1988) 1521

13. P. J. WEBSTER, K. R. A. ZIEBECK, S. L. TOWN and M. S. PEAK, Philos. Mag. B 49 (1984) 295.

14. S. MIY AZA KI and K. OTS U KA, ISIJ Intern. 29 (1989) 353

15. T. Y. HS U, "Martensitic Transformation and Martensite," 2nd ed. (Science Press, Beijing, China, 1999) Chaps. 1, p. 64.

Received 29 January

and accepted 23 June 2004 